\title{
Characterization of a New Tailoring Domain in Polyketide Biogenesis: The Amine Transferase Domain of MycA in the Mycosubtilin Gene Cluster
} Zachary D. Aron, ${ }^{\ddagger}$ Pieter C. Dorrestein
, Jonathan R. Blackhall
Walsh ${ }^{*, \neq}$

Department of Biological Chemistry and Molecular Pharmacology, Harvard Medical School, 240 Longwood Avenue, Boston, Massachusetts 02115, and Department of Chemistry, University of Illinois, 600 South Mathews Avenue, Urbana, Illinois 61801

\section{Supporting Information}

\section{Contents}

I. Bacterial strains, plasmids, materials and instrumentation $\quad$ s2

II. Preparation of mycA4N5, mycA6N7 and mycA4N7 overexpression constructs.

a. Isolation of genomic DNA $\quad \mathrm{s} 2$

b. Cloning of $m y c \mathrm{~A} 4 \mathrm{~N} 5, m y c \mathrm{~A} 6 \mathrm{~N} 7$ and $m y c \mathrm{~A} 4 \mathrm{~N} 7$ genes $\quad \mathrm{s} 2$

III. Overproduction and purification of MycA4N5, MycA6N7 and MycA4N7 s2

IV. Phosphopantetheinylation of MycA4N7 by trichloroacetic acid (TCA) precipitation s3

V. Identification of PLP loading in MycA4N7

a. Titration with PLP $\quad$ s4

b. Formation of the hydroxylamine-PLP oxime s4

VI. UV-analysis of amine transfer to MycA4N7 at varying glutamine and alanine concentrations $\quad$ s5

VII. Synthesis of alanine from radiolabeled sodium pyruvate $\quad$ s6

VIII. Identification of $\beta$-aminobutyrate as amine transfer product by OPA derivatization $\quad$ s6

IX. FTMS Studies

a. Mapping the active sites of MycA4N7 $\quad$ s7

b. Amine transfer activity observed by FTMS $\quad$ s9

c. Amine donor screen $\quad$ s10

d. Alpha or amide nitrogen from glutamine as amine source $\quad \mathrm{s} 12$

e. Time course $\mathrm{ACP}_{2}$ and $\mathrm{PCP}_{1}$ with $\alpha-{ }^{15} \mathrm{~N}-\mathrm{Gln} \quad \mathrm{s} 12$

f. Reversibility of the amine transfer to MycA4N7 $\quad$ s14

X. Scheme S1: Mechanism of PLP mediated amine transfer $\quad$ s16 


\section{Bacterial strains, plasmids, materials and instrumentation}

Chemically competent TOP10 and B121 (DE3) E. coli were available from Invitrogen. Ready Gel 4-15\% Tris-HCl gels were purchased from BioRad. The pET28a plasmid was purchased from Novagen. All restriction endonucleases and T4 DNA ligase were obtained from New England Biolabs. Synthetic DNA oligonucleotides were purchased from Integrated DNA Technologies and used without further purification. Polymerase chain reactions (PCR) were run using Pfu Turbo DNA polymerase from Strategene. Ni-NTA chromatography resin was obtained from Quiagen. Genomic DNA was purified using the Dneasy kit from Quiagen. Other DNA isolation was performed using a QIAprep Spin Miniprep Kit Protocol from Quiagen. DNA sequencing was performed at the Molecular Biology Core Facilities Dana-Farber Cancer Institute (Boston, MA). $\left[1-{ }^{14} \mathrm{C}\right]$ Sodium pyruvate was purchased from American Radiolabeled Chemicals. $\left[1-{ }^{14} \mathrm{C}\right]$ Acetyl-CoA was obtained from Amersham Biosciences. All other materials were purchased from Sigma Aldrich.

\section{Preparation of mycA4N5, mycA6N7 and mycA4N7 overexpression constructs}

\section{a. Isolation of genomic DNA}

Bacillus Subtilis was obtained from ATCC (strain 6633), inoculated in nutrient broth and grown at 30 ${ }^{\circ} \mathrm{C}$ for $24 \mathrm{~h}$ with agitation. Genomic DNA was isolated using the Dneasy prep (Quiagen).

\section{b. Cloning of mycA4N5, mycA6N7 and mycA4N7 genes}

Amplification of the mycA4N5 open reading frame from genomic DNA was accomplished using Pfu Turbo DNA polymerase using primers MN1 (5'-GCA TTG GCT AGC AAT CAT ACG AAG ACA CAT ATT G-3') and MC1 (5'-CCC TTC GTC GAC AAA TCC GCC GCG GCG-3'). NheI and SalI restriction sites are underlined. The resulting $1.9 \mathrm{~kb}$ PCR product was purified by agarose gel electrophoresis, digested with NheI and SalI and ligated into similarly digested pET28a, yielding a construct pET28a-MycA4N5 with an $N$-terminal hexahistidine tag. The similar constructs pET28aMycA6N7 and pET28a-MycA4N7, both with $N$-terminal hexahistidine tags, were generated in an analogous manner using primers MN2 (5'-CGC GGC GCT AGC ATT CCA GAA GGG CCG-3') and MC2 (5'-AGC TGG GTC GAC TCA GTA AAA GGC TTT CTG-3') for construct pET28a-MycA6N7 (1.7 kb insert) and primers MN1 and MC2 for construct pET28a-MycA4N7 (3.6 kb insert).

Expression plasmids pET28a-MycA4N5, pET28a-MycA6N7 and pET28a-MycA4N7 were transformed into E. coli strain Top10 and grown in LB medium supplemented with kanamycin (50 $\mu \mathrm{g} / \mathrm{mL}$ ). Sequencing of selected colonies containing pET28a-MycA4N5, pET28a-MycA6N7 and pET28a-MycA4N7 identified colonies that had inserts with sequences identical to the corresponding gene sequence from Bacillus subtilis ATCC 6633 reported by Duitman and coworkers. The nomenclature used in naming MycA4N7 is the following: the name of the parent protein followed by the number of the first domain, either an $\mathrm{N}$ or $\mathrm{C}$ to denote the location of the His tag and the last domain used in the fragment.

\section{Overproduction and purification of MycA4N5, MycA6N7 and MycA4N7}

The expression plasmids were transformed into E. coli strain BL21(DE3) and grown in LB medium supplemented with $50 \mu \mathrm{g} / \mathrm{mL}$ of kanamycin. Each liter of culture was inoculated with a $10 \mathrm{~mL}$ overnight starter culture. Cultures were grown at $37^{\circ} \mathrm{C}$ to an $\mathrm{OD}_{600}$ of $0.2-0.25$, temperature shifted to 
$15^{\circ} \mathrm{C}$ for $1 \mathrm{~h}$, induced with $100 \mu \mathrm{M}$ iPTG, and incubated at $15^{\circ} \mathrm{C}$ for an additional $17 \mathrm{~h}$. Cells were harvested by centrifugation $(15 \mathrm{~min}$ at $5000 \mathrm{~g}$ ), resuspended in lysis buffer [ $400 \mathrm{mM} \mathrm{NaCl}, 25 \mathrm{mM}$ Tris $(\mathrm{pH}=8.00)$, and $10 \%$ glycerol], and lysed by one passage through a french press at $8000-12000 \mathrm{psi}$. Ni-NTA resin $(1.7 \mathrm{~mL}$ slurry per $3 \mathrm{~L}$ of culture) was added to the clarified lysate and allowed to batch bind for $1 \mathrm{~h}$ at $4{ }^{\circ} \mathrm{C}$. The resin was washed with 5 column volumes of $2 \mathrm{mM}$ imidazole in lysis buffer. The proteins were eluted with a step gradient of increasing imidazole concentrations in lysis buffer (5, 20, 40, 60 and $200 \mathrm{mM}$ ). MycA4N5, MycA6N7 and MycA4N7 typically eluted in the 60 and $200 \mathrm{mM}$ fractions as bands with $\mathrm{MW}=71.2 \mathrm{kDa}, 64.7 \mathrm{kDa}$ and $135.9 \mathrm{kDa}$ respectively (Figure s1). These fractions were pooled, concentrated and dialyzed at $4{ }^{\circ} \mathrm{C}$ in two $3 \mathrm{~h}$ steps: $3 \mathrm{~h}[300 \mathrm{mM} \mathrm{NaCl}, 50 \mathrm{mM}$ Tricine $(\mathrm{pH}=8.00)$, and $10 \%$ glycerol]. Concentrated protein solutions were stored at $-80{ }^{\circ} \mathrm{C}$. Protein concentrations were determined using the Bradford assay (Bio-Rad).

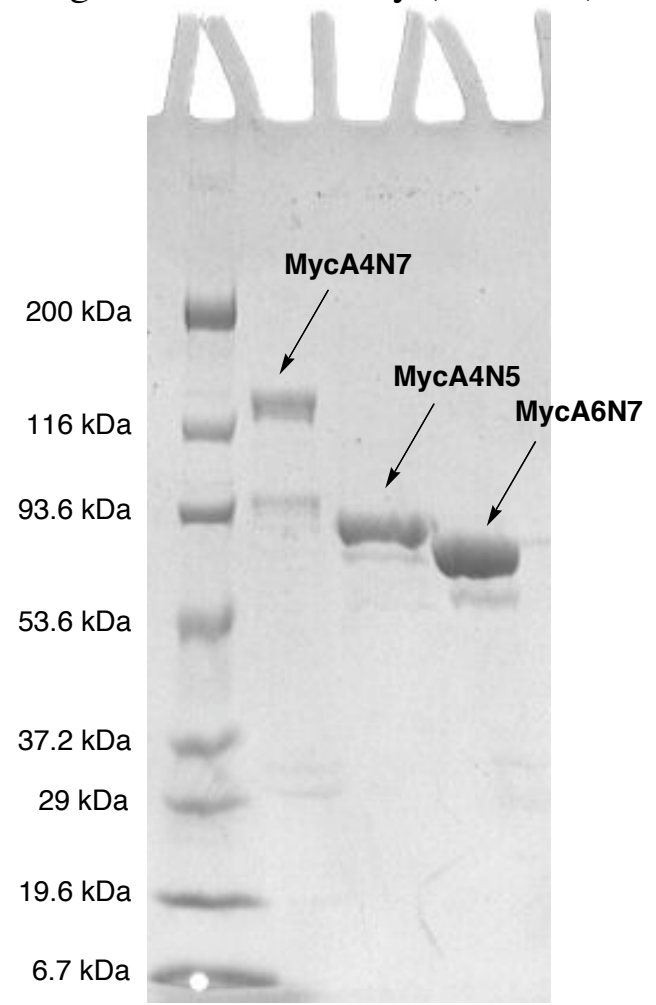

Figure s1. Analytical gel electrophoresis of MycA4N5, MycA6N7 and MycA4N7

MycA4N7 was accessed in the reduced (PMP) form by a 5 step dialysis procedure following Ni-NTA purification: $2 \mathrm{X} 3 \mathrm{~h}$ in $300 \mathrm{mM} \mathrm{NaCl}, 50 \mathrm{mM}$ Tricine $(\mathrm{pH}=8.00), 10 \mathrm{mM}$ glycine and $10 \%$ glycerol followed by $3 \mathrm{X}$ 3h in $300 \mathrm{mM} \mathrm{NaCl}, 50 \mathrm{mM}$ Tricine $(\mathrm{pH}=8.00)$ and $10 \%$ glycerol.

Samples of MycA4N7 used for FTMS studies were generated in a similar manner. Differences in protein expression were as follows: Cells were lysed in a lysis buffer [100 mM NaCl, $25 \mathrm{mM}$ Tris $(\mathrm{pH}=8.00)$, and $10 \%$ glycerol] by sonication in the presence of lysozyme. Following purification, the purified construct was buffer exchanged with a PD-10 gel filtration column (Amersham Bioscience) with a storage buffer [1 mM TCEP, $100 \mathrm{mM} \mathrm{NaCl}, 25 \mathrm{mM}$ Tris $(\mathrm{pH}=8.00)$, and 10\% glycerol].

\section{Phosphopantetheinylation of MycA4N7 by trichloroacetic acid (TCA) precipitation}

The phosphopantetheinylation of MycA4N7 was examined at three different concentrations of MycA4N7 $(2.5 \mu \mathrm{M}, 5 \mu \mathrm{M}$ and $10 \mu \mathrm{M})$ under otherwise constant conditions. Reactions were run at room 
temperature in $385 \mu \mathrm{L}$ of buffer [ $50 \mathrm{mM}$ Tris $(\mathrm{pH}=7.5), 50 \mathrm{mM} \mathrm{NaCl}, 5 \mathrm{mM} \mathrm{MgCl} \mathrm{m}_{2}$ and $5 \mathrm{mM}$ TCEP] with $50 \mu \mathrm{M}\left[1-{ }^{14} \mathrm{C}\right] \mathrm{AcCoA}(22.7 \mathrm{Ci} / \mathrm{mol})$ and $100 \mathrm{nM}$ sfp. Reactions were initiated by the addition of sfp. At $0,2,5,10,30,60$ and $120 \mathrm{~min}, 50 \mu \mathrm{L}$ of the reaction mixture was quenched into $500 \mu \mathrm{L}$ of $10 \%$ (v/v) TCA. The protein was collected by centrifugation, the resultant pellets washed with $500 \mu \mathrm{L}$ of $10 \%(\mathrm{v} / \mathrm{v}) \mathrm{TCA}$, dissolved in $100 \mu \mathrm{L}$ of formic acid, added to scintillation fluid and counted. The amount of bound radioactivity was converted to \% conversion (based on 1 equivalent of $\left[1-{ }^{14} \mathrm{C}\right] \mathrm{AcCoA}$ binding to 1 equivalent to MycA4N7) using the specific activity of $\left[1-{ }^{14} \mathrm{C}\right] \mathrm{AcCoA}$ (Figure s2).

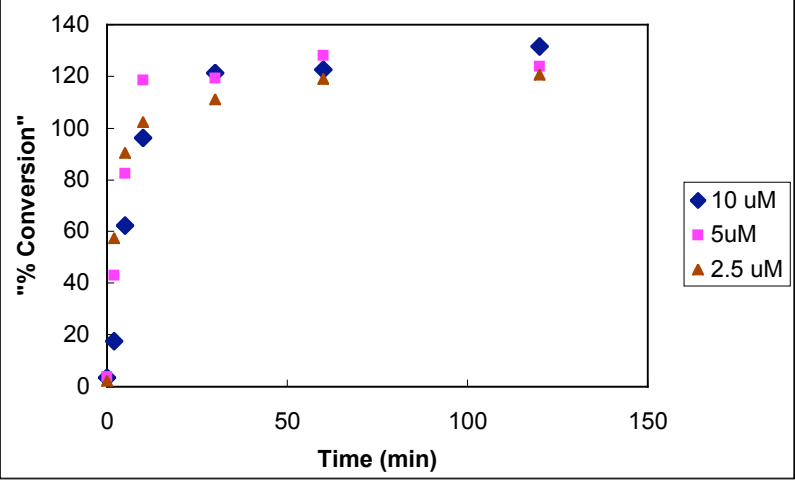

Figure s2. Phosphopantetheinylation of MycA4N7 with $\left[1-{ }^{14} \mathrm{C}\right] \mathrm{AcCoA}$.

\section{Identification of PLP loading in MycA4N7}

\section{a. Titration with PLP}

Titration of PLP bound to MycA4N7 was examined in triplicate at room temperature. Reactions were examined with $35 \mu \mathrm{M}$ MycA4N7 in $200 \mu \mathrm{L}$ of buffer [50 mM HEPES (pH = 8.00)] (Figure s3). PLP was added in $1 \mu \mathrm{L}$ aliquots (700 $\mu \mathrm{M}, 0.1$ equivalents), and monitored by UV absorbance at 419 $\mathrm{nm}$. A standard curve (not shown) was generated by adding $1 \mu \mathrm{L}$ aliquots of PLP (700 $\mu \mathrm{M})$ to a $200 \mu \mathrm{L}$ HEPES (50 mM) solution while monitoring at $419 \mathrm{~nm}$. The \% PLP loading was determined by examining the line resultant from subtracting the standard curve from the titration (Figure s3).

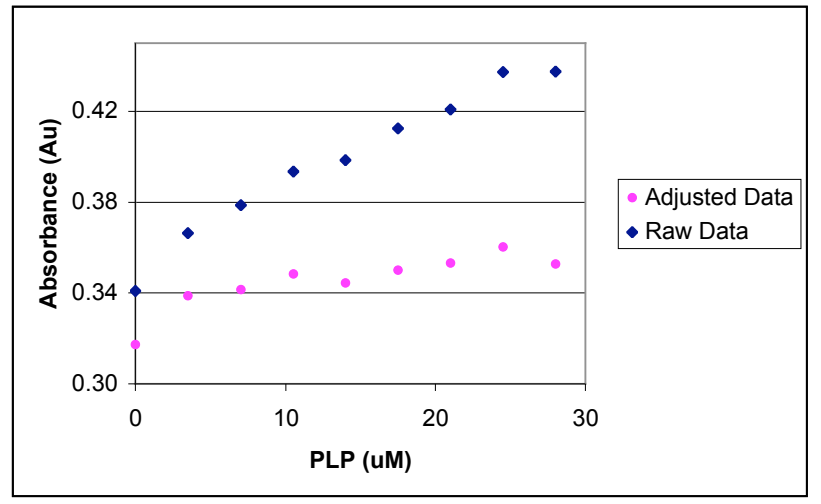

Figure s3. Titration of MycA4N7 with PLP.

\section{b. Formation of the hydroxylamine-PLP oxime}

The reaction of MycA4N7 with hydroxylamine was examined at room temperature with $28 \mu \mathrm{M}$ of MycA4N7 and $5 \mathrm{mM}$ hydroxylamine in $200 \mu \mathrm{L}$ of buffer [ $50 \mathrm{mM}$ Tris $(\mathrm{pH}=8.00)]$. UV-vis spectra were taken in the presence and absence of hydroxylamine (Figure s4). 


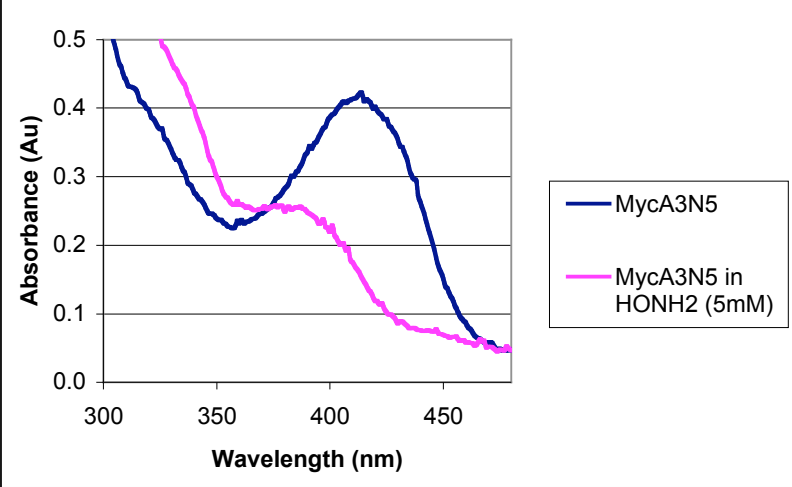

Figure s4. Reaction of MycA4N7 with hydroxylamine.

\section{UV-analysis of amine transfer to MycA4N7 at varying glutamine and alanine concentrations}

Studies of the amine transfer from glutamine and alanine to MycA4N7 were performed using a constant concentration of MycA4N7 $(10 \mu \mathrm{M})$ and varying concentrations of the amino acids $(10,40$ and $160 \mu \mathrm{M}$ gln and 160, 640 and $2240 \mu \mathrm{M}$ ala) in $250 \mu \mathrm{L}$ of buffer [ $25 \mathrm{mM}$ Tris $(\mathrm{pH}=8.00), 50 \mathrm{mM}$ $\mathrm{NaCl}$. Reactions were initiated by the addition of $245 \mu \mathrm{L}$ of a buffered stock solution of MycA4N7 to cuvettes containing the amino acid in $5 \mu \mathrm{L}$ of water, and the reactions monitored at $25^{\circ} \mathrm{C}$ by $\mathrm{UV}$-vis periodically over the course of $9 \mathrm{~h}$ (representative reactions shown, Figure s5). All reactions reached a static point within $2 \mathrm{~h}$, and the activity of the protein after $9 \mathrm{~h}$ was confirmed by the further addition of 5 $\mu \mathrm{L}$ of $10 \mathrm{mM}$ gln (not shown), which resulted in further amine transfer (with the exception of the sample containing $160 \mu \mathrm{M}$ gln. Figure s6 shows UV spectra of the proteins at the $2 \mathrm{~h}$ point as well as the initial UV spectra of MycA4N7.

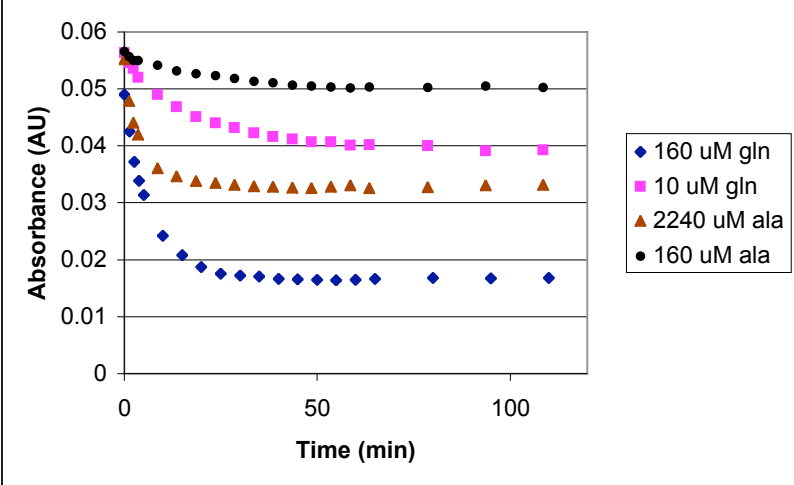

Figure s5. Amine Transfer to MycA4N7 Over Time (Absorption at 419 nm) 


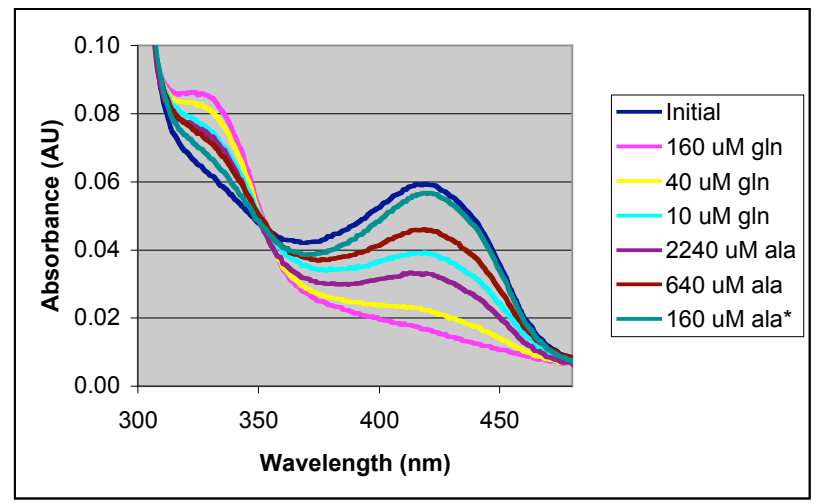

*This data set had an air bubble that slightly offset the data; data shown was multiplied by a factor of 1.13 to offset this.

Figure s6. UV spectra of MycA4N7 after $2 \mathrm{~h}$ in the presence of varying amounts of amino acids.

\section{Synthesis of alanine from radiolabeled sodium pyruvate}

The conversion of $\left[1-{ }^{14} \mathrm{C}\right]$ sodium pyruvate to $\left[1-{ }^{14} \mathrm{C}\right]$ alanine by reaction with the PMP form of MycA4N7 was examined with $21.8 \mu \mathrm{M}$ MycA4N7 and $100 \mu \mathrm{M}\left[1-{ }^{14} \mathrm{C}\right]$ sodium pyruvate $(3.5 \mathrm{Ci} / \mathrm{mol})$ in $120 \mu \mathrm{L}$ of buffer [50 mM Tris $(\mathrm{pH}=7.5), 50 \mathrm{mM} \mathrm{NaCl}]$. Two control reactions, one without mycA4N7 and one without $\left[1-{ }^{14} \mathrm{C}\right]$ sodium pyruvate were also run. Reactions were initiated by the addition of [1${ }^{14} \mathrm{C}$ ]sodium pyruvate. Reactions were run at room temperature for $30 \mathrm{~min}$, at which point residual protein was removed by filtration through 30,000 MW nylon filters ( 24 min, 13,000g). Products were derivatized with $o$-phthalaldehyde and 3-mercaptopropionic acid to ease identification of $\left[1-{ }^{14} \mathrm{C}\right]$ alanine. OPA derivatization was carried out on the entire reaction mixture by addition of $12 \mu \mathrm{L}$ of $0.4 \mathrm{M}$ borate buffer $(\mathrm{pH}=10.4$ ) and $2 \mu \mathrm{L}$ of the OPA derivatization mixture [75 mM $o$-phthalaldehyde, $225 \mathrm{mM} \mathrm{3-}$ mercaptopropionic acid, $0.35 \mathrm{M}$ borate buffer $(\mathrm{pH}=10.4), 10 \% \mathrm{MeOH}$ in water]. A sample of the OPA derivative of alanine was generated in a similar manner. These mixtures were directly injected onto a C18 HPLC column; dual online UV (338 nm) and radioisotope detectors (tuned to ${ }^{14} \mathrm{C}$ ) were used to detect the products. The HPLC was run with the following gradient: 0-60\% B in 20 min, Buffer $\mathrm{A}=40$ $m \mathrm{man}_{2} \mathrm{PO}_{4}(\mathrm{pH}=7.80)$, Buffer $\mathrm{B}=$ acetonitrile:MeOH: $\mathrm{H}_{2} \mathrm{O}=45: 45: 10$ (Figure s7).

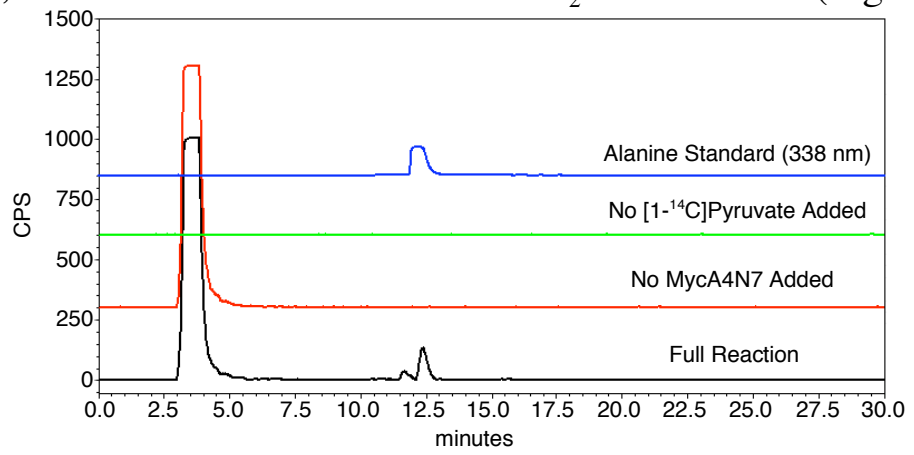

Figure s7. HPLC Analysis of Alanine Formation from Pyruvic Acid.

\section{Identification of $\beta$-aminobutyrate as amine transfer product by OPA derivatization}

Amine transfer reactions were performed with $50 \mu \mathrm{M}$ MycA4N7 in $300 \mu \mathrm{L}$ of buffer [50 mM Tricine $(\mathrm{pH}=8.00), 50 \mathrm{mM} \mathrm{NaCl}, 5 \mathrm{mM} \mathrm{MgCl}_{2}, 5 \mathrm{mM}$ TCEP, $0.5 \mathrm{mM}$ gln] with $100 \mu \mathrm{M}$ acetoacetyl $\mathrm{CoA}$ and $1 \mu \mathrm{M}$ sfp. Two control reactions, one without mycA4N7 and one without gln were also run. 
Reactions were initiated by the addition of sfp and maintained at $25^{\circ} \mathrm{C}$. After reaction for $18 \mathrm{~h}, 30 \mu \mathrm{L}$ of $\mathrm{KOH}(1 \mathrm{M})$ was added and the reactions heated to $60{ }^{\circ} \mathrm{C}$ for $20 \mathrm{~min}$ to cleave the thioesters products from the enzyme. Residual protein was removed by filtration through 10,000 MW nylon filters ( $24 \mathrm{~min}$, $13,000 \mathrm{~g}$ ). The products were then derivatized with $o$-phthalaldehyde and 3-mercaptopropionic acid to ease identification of $\beta$-aminobutyrate. OPA derivatization was carried out on $110 \mu \mathrm{L}$ aliquots of the reaction mixtures by addition of $12 \mu \mathrm{L}$ of $0.4 \mathrm{M}$ borate buffer $(\mathrm{pH}=10.4)$ and $2 \mu \mathrm{L}$ of the OPA derivatization mixture $[75 \mathrm{mM} o$-phthalaldehyde, $225 \mathrm{mM} \mathrm{3-mercaptopropionic} \mathrm{acid,} 0.35 \mathrm{M}$ borate buffer $(\mathrm{pH}=10.4), 10 \% \mathrm{MeOH}$ in water]. These mixtures were directly injected onto a C18 HPLC column with in line UV detection at $338 \mathrm{~nm}$. The HPLC was run with the following gradient: 0-60\% B in $20 \mathrm{~min}$, Buffer $\mathrm{A}=40 \mathrm{mM} \mathrm{Na} \mathrm{PO}_{4}(\mathrm{pH}=7.80)$, Buffer $\mathrm{B}=$ acetonitrile: $\mathrm{MeOH}: \mathrm{H}_{2} \mathrm{O}=45: 45: 10$ (Figure s8). The presence (and in the controls, absence) of the OPA derivative of $\beta$-aminobutyrate was unambiguously identified by both retention time and co-injection (not shown).

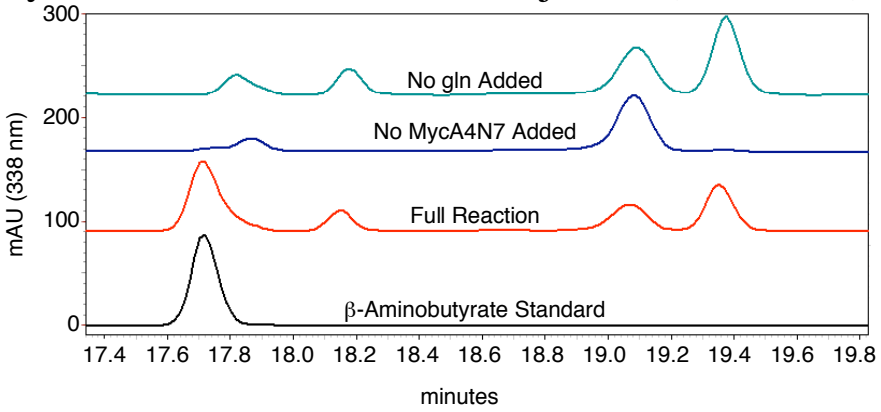

Figure s8. HPLC analysis of OPA Derivative of $\beta$-Aminobutyrate.

\section{FTMS studies}

\section{a. Mapping the active sites of MycA4N7}

MycA4N7 $(185 \mu \mathrm{g})$ was reacted for two hours at room temperature in the presence of $3.6 \mu \mathrm{M}$ Sfp, $8 \mathrm{mM} \mathrm{MgCl}$, and $466 \mu \mathrm{M}$ Acetoacetyl-CoA (SIGMA-ALDRICH) in a total reaction volume of $300 \mu 1$. The final product was digested with trypsin at $\mathrm{pH} 8.0$ (sequence grade trypsin $(85 \mathrm{U}, 1 \mathrm{U}$ is defined as the amount of Sequencing Grade Modified Trypsin required to produce a $\Delta \mathrm{A}_{253}$ of 0.001 per minute at $30^{\circ} \mathrm{C}$ with the substrate $\alpha$-benzoyl-L-arginine ethyl ester. The substrate is dissolved in $50 \mathrm{mM}$ Tris- $\mathrm{HCl}$ at $\mathrm{pH} 7.6$ with $1 \mathrm{mM} \mathrm{MgCl}$ and the enzyme is diluted in $50 \mathrm{mM}$ acetic acid, $5 \mu \mathrm{g}$ Promega for 10 minutes, which was stopped by acidifying with $50 \mu \mathrm{L}$ of $10 \%$ formic acid.

The reaction was purified by HPLC (Phenomenex Jupiter $5 \mu \mathrm{C} 4300 \AA$ column) on an HP1100 HPLC using a 60 minute gradient (Table 1) collecting fractions at 1 min intervals. The resulting fractions were redissolved in $100 \mu \mathrm{l}$ of $78 \%$ acetonitrile, $0.1 \%$ TFA and analyzed by ESI-FTMS. A mass peak-list of all the observed ions was generated using the software Thrash and/or manual deconvolution of the charge states. The generated peak-list was imported into the freeware PAWS in which the active site serine masses were adjusted so to reflect the addition of PPant and acetoacetate $(+424.1 \mathrm{Da})$. Once a match to the active site was obtained, the active sites were subjected to OCAD, IRMPD or ECD. The resulting fragment ions from OCAD, IRMPD and ECD were then analyzed using ProSightPTM to verify that they were indeed the active sites. Using this methodology, we found one $\mathrm{ACP}_{2}$ active site in fraction 37 and the $\mathrm{PCP}_{1}$ active site in fraction 32. 


\begin{tabular}{|l|l|l|l|l|l|l|l|l|l|l|l|}
\hline $\begin{array}{l}\text { Time } \\
(\mathrm{min})\end{array}$ & 0.00 & 10.0 & 15.0 & 55.0 & 60.0 & 60.1 & 60.2 & 62.6 & 63.0 & 65.0 & 66.0 \\
\hline$\% \mathrm{~A}$ & 90 & 90 & 70 & 30 & 10 & 10 & 95 & 95 & 5 & 5 & 90 \\
\hline$\% \mathrm{~B}$ & 10 & 10 & 30 & 70 & 90 & 90 & 5 & 5 & 95 & 95 & 10 \\
\hline
\end{tabular}

Table s1. HPLC Gradient for active site purification, Solvent A is water with $0.1 \%$ TFA and Solvent B is acetonitrile with $0.1 \%$ TFA. 


\section{PCP}

AVYEEPENETELQIAQIWAELLGLEKVGRS DHFLSLGGNSLKATLMLSKIQQTFNQKVSI GQFFSHQTVKELANFIRGEKNVK

PCP

Fraction 32

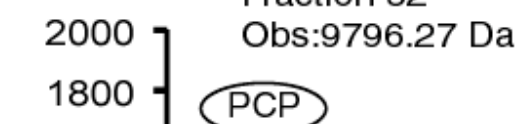

GSHMASNHTKTHIESFLKTVISNASGIRAD

EIDSNAHFIGFGLDSIMLTQVKKAIADEFN

VDIPMERFFDTMNNIESVVDYLAENVPSAA STPPQESVTAQEELVISGAQPELEHQEHML

DK

\section{$\mathrm{ACP}$}

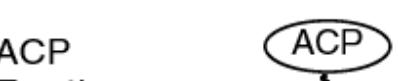

ACP

Fraction 37

Obs: $13,843.5 \mathrm{Da}$
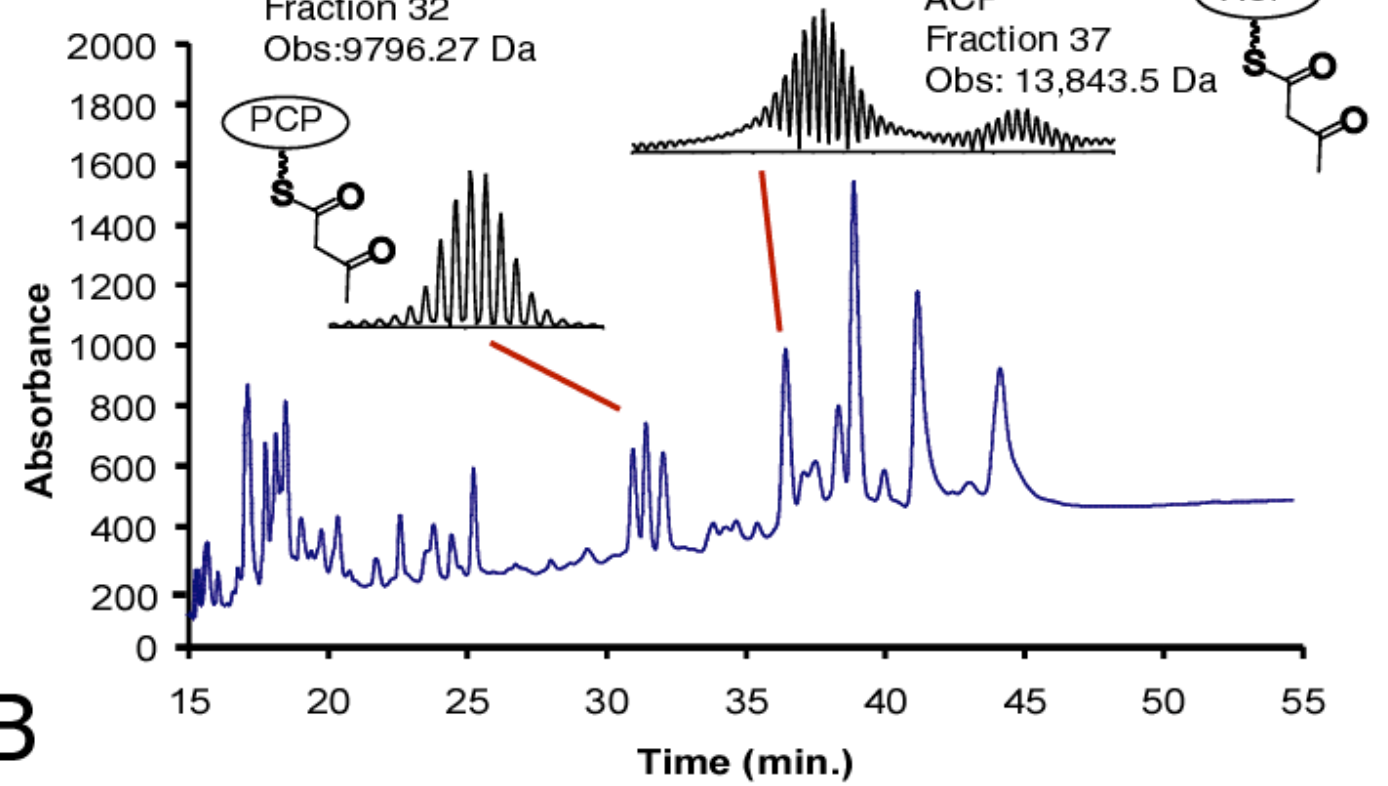

Figure s9. Active site mapping for mycA4N7. A) HPLC with the spectra and sequences of the $\mathrm{ACP}_{2}$ and $\mathrm{PCP}_{1}$ domain. $\mathrm{B}$ ) $\mathrm{OCAD}$ verification of the $\mathrm{PCP}_{1}$ active site. $\mathrm{C}$ ) $\mathrm{ECD}$ verification of the $\mathrm{ACP}_{2}$ active site.

\section{b. Amine transfer activity observed by FTMS}

The MycA4N7 $(450 \mu \mathrm{g})$ was reacted for two hours at room temperature in the presence of 3.6 $\mu \mathrm{M} \mathrm{Sfp}, 8 \mathrm{mM} \mathrm{MgCl}$, and $466 \mu \mathrm{M}$ Acetoacetyl-CoA and a mixture of proteinogenic amino acids (1.33 $\mathrm{mM}$ concentration), in a total reaction volume of $300 \mu \mathrm{l}$. Some precipitation was observed in this 
reaction. The final product was digested with trypsin for 10 minutes, quenched with $50 \mu 1$ of $10 \%$ formic acid and analyzed as described during the mapping of the active sites. In this reaction the $\beta$ aminobutyryl-S-ACP 2 active site eluted by HPLC at $35.5 \mathrm{~min}$. and was confirmed by ECD while the $\beta$ aminobutyryl-S-PCP ${ }_{1}$ site eluted in fraction 31 (30 to $31 \mathrm{~min}$.) and was verified using OCAD.

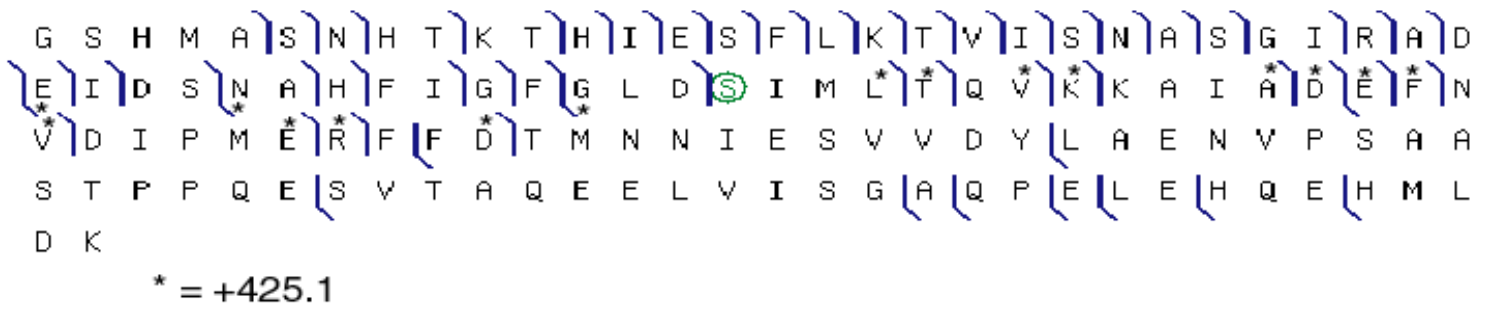

Figure s10. Localization of the aminobutyryl functionality (+1 Da) by ECD. Representative fragment ions are shown in Figure 1.

\section{c. Amine donor screen}

Following the observation of the amine transfer by HPLC of the trypsin digest and confirmation by ESI-FTMS, the HPLC assay was used to establish which amino acid was the most efficient amine donor using the increase of the newly formed peak at $35.5 \mathrm{~min}$ in the HPLC trace. This was done in two stages. In the first stage, 5 groups of 3-4 amino acids (the amino acids had a concentration of $2.0 \mathrm{mM}$ ) were prepared and incubated with acetoacetyl-S-MycA4N7 (35 mM Tris, $\mathrm{pH}=7.8,450 \mu \mathrm{g}, 300 \mu \mathrm{L})$ for 2 hours at which point $5 \mu \mathrm{g}$ of sequence grade trypsin $(85 \mathrm{U})$ was added and allowed to digest for 5 min. at $\mathrm{pH} 8.0$ before the addition of $50 \mu \mathrm{L}$ of $10 \%$ formic acid. Each reaction was analyzed by HPLC and the $35.5 \mathrm{~min}$ fraction (Fraction 36) was analyzed by FTMS to ensure that $\beta$-aminobutyryl-S-ACP ${ }_{2}$ had formed. All of the groups displayed amine transfer but the two best groups contained Ala, Glu, Arg, Gln and Met, Tyr, Ser, Trp. Therefore each of the 8 amino acids were screened separately in a reaction containing $1.2 \mathrm{mM}$ of the amino acid and acetoacetatyl-S-MycA4N7 (40 mM Tris, pH=7.8, $450 \mu \mathrm{g}, 300 \mu \mathrm{L}$ ) for 30 min before treatment with trypsin and HPLC separation. Using the increase at $35.5 \mathrm{~min}$, Gln was identified as the most efficient amine donor. 
A

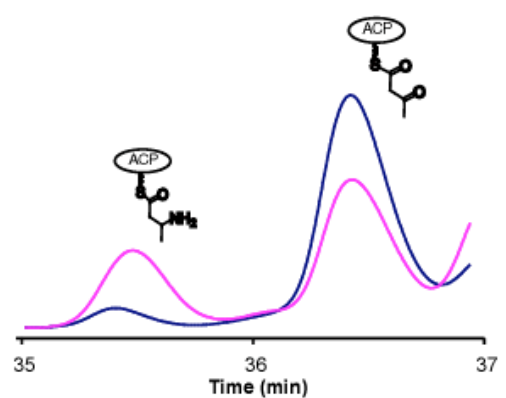

B
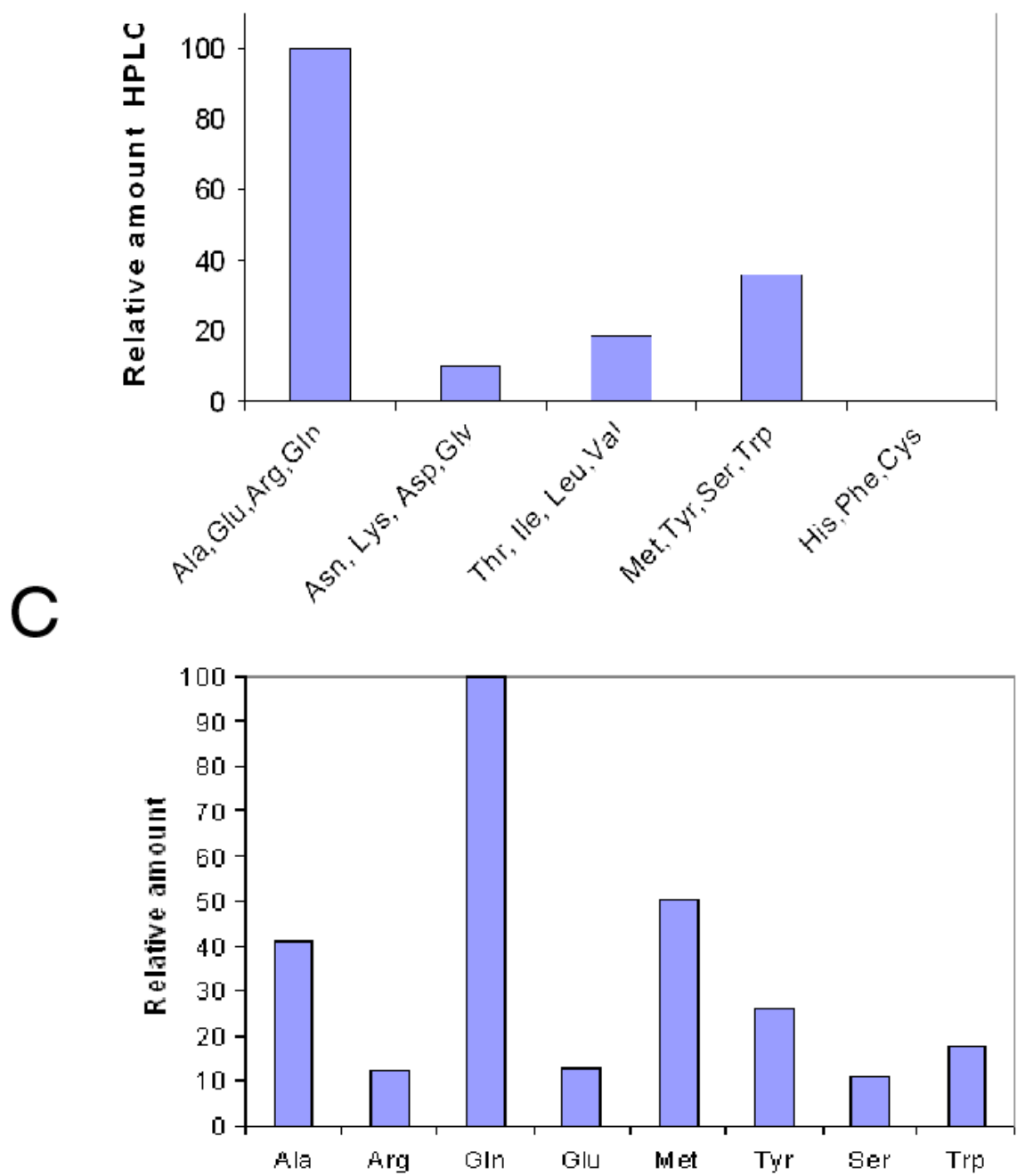

Figure s11. Identification of the most efficient amine donor by HPLC. A) a representative HPLC with (blue trace) and without amine source, the most efficient amine donor was characterized by the largest increase at $35.5 \mathrm{~min}$. B) Grouped substrates. C) Individual amino acids. 


\section{d. Alpha or amide nitrogen from glutamine as amine source}

Because glutamine was found to be the most active amine donor, the question arose whether the alpha or amide nitrogen was transferred to the nascent product. Both of the corresponding ${ }^{15} \mathrm{~N}$ labeled amines were tested so that a corresponding $2 \mathrm{Da}$ shift when a ${ }^{15} \mathrm{~N}$ is transferred as opposed to a $1 \mathrm{Da}$ increase when it is ${ }^{14} \mathrm{~N}$, which can be monitored by ESI-FTMS and tandem mass spectrometry (OCAD). The ${ }^{15} \mathrm{~N}$-labeled glutamine constructs were screened separately in a reaction containing 1.2 $\mathrm{mM}$ of the amino acid and acetoacetyl-S-MycA4N7 (40 mM Tris, $\mathrm{pH}=7.8,300 \mu \mathrm{l}$ ) for $30 \mathrm{~min}$ before treatment with trypsin.

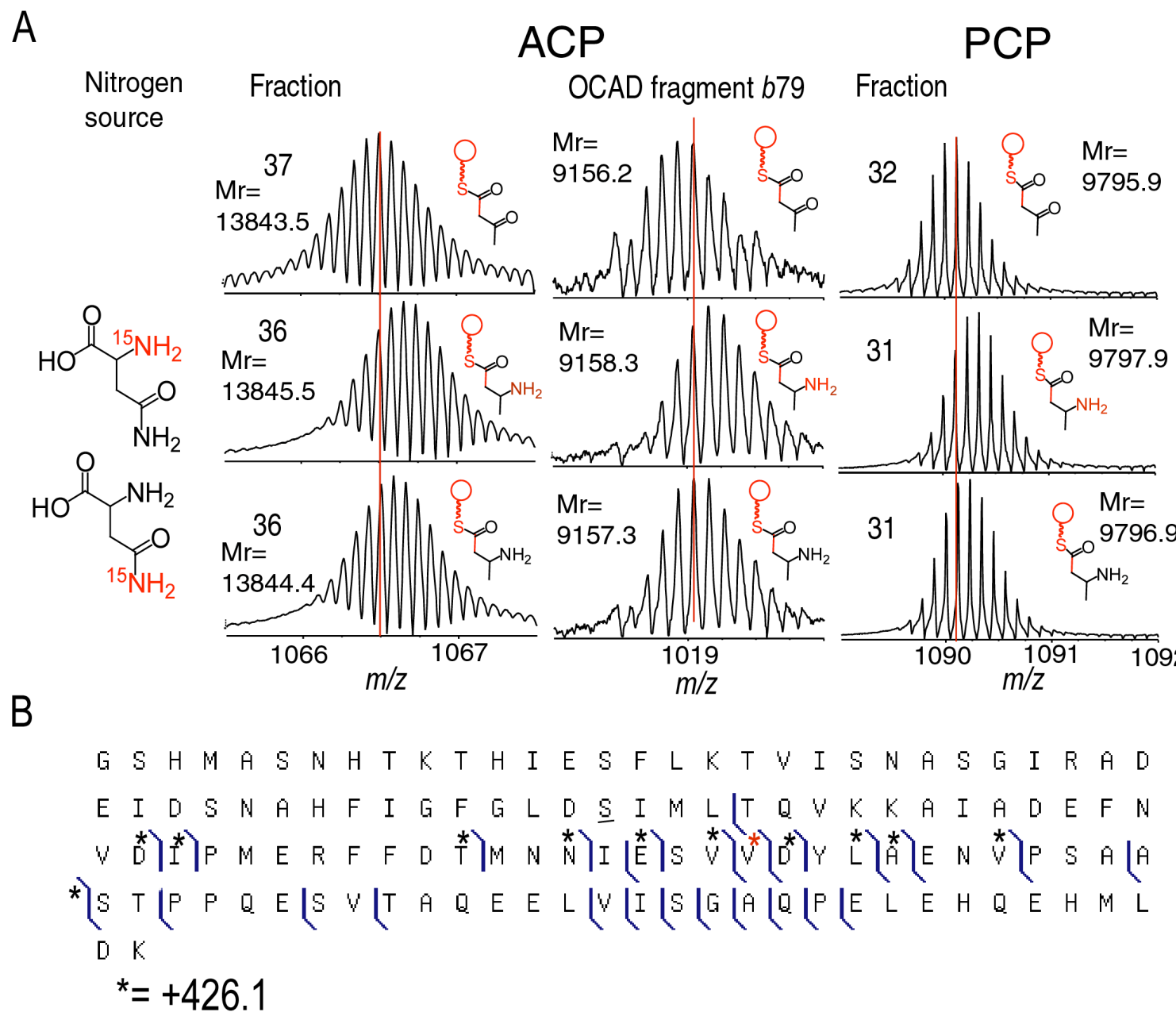

Figure s12. The origin of the nitrogen from Gln. A) Shows the 2 Da increase and fraction shift when incubated with $\alpha-{ }^{15} \mathrm{~N}-$ Gln and 1 Da increase with $\gamma-{ }^{15} \mathrm{~N}-\mathrm{Gln}$. The red lines are there to visualize the 1 or 2 Da shifts. B) OCAD fragmentation ion map for the aminobutyryl-S- $\mathrm{ACP}_{2}$ from the incubation with _${ }^{15} \mathrm{~N}-\mathrm{Gln}$. The red $*$ in between the VD is the fragment shown in figure $\mathrm{A}$. The underlined $\mathrm{S}$ is the active site serine.

\section{e. Time course $\mathrm{ACP}_{2}$ and $\mathrm{PCP}_{1}$ with $\alpha-{ }^{15} \mathrm{~N}-\mathrm{Gln}$}

A reaction containing $1.45 \mathrm{mg}$ of MycA4N7 was incubated with $4 \mu \mathrm{M}$ of Sfp, $8 \mathrm{mM}$ of $\mathrm{MgCl}_{2}$, and acetoacetyl CoA (1.6 ml total volume) for 1 hour before it was treated with $2 \mathrm{mM}$ of $\alpha{ }^{-15} \mathrm{~N}-\mathrm{Gln}$. 
At $0.33,0.66,1,2,4,8,16$, and $32 \mathrm{~min}, 68$ units of sequence grade trypsin in $50 \mathrm{mM}$ acetic acid and 12 $\mu \mathrm{l}$ of $1 \mathrm{M}$ Tris, $\mathrm{pH} 8.0$ was added to $200 \mu \mathrm{l}$ of the reaction and incubated for $5 \mathrm{~min}$ before $50 \mu 1$ of $10 \%$ sodium formate was added. Subsequently, the digest was purified by HPLC (Figure s13A) and fractions 30 and 31 as well as 36 and 37 were analyzed by ESI-FTMS.

A

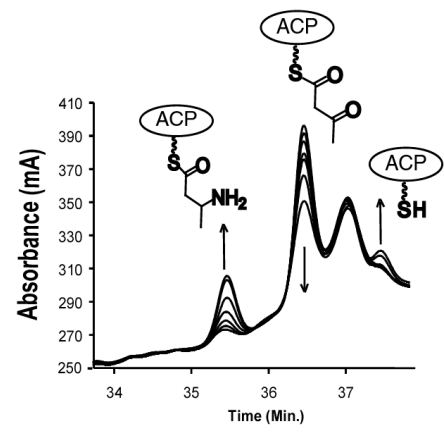

B

Time (min.)

Fraction 36 and $37 \quad$ Fraction 31 and 32 $(\mathrm{ACP})$ (PCP)

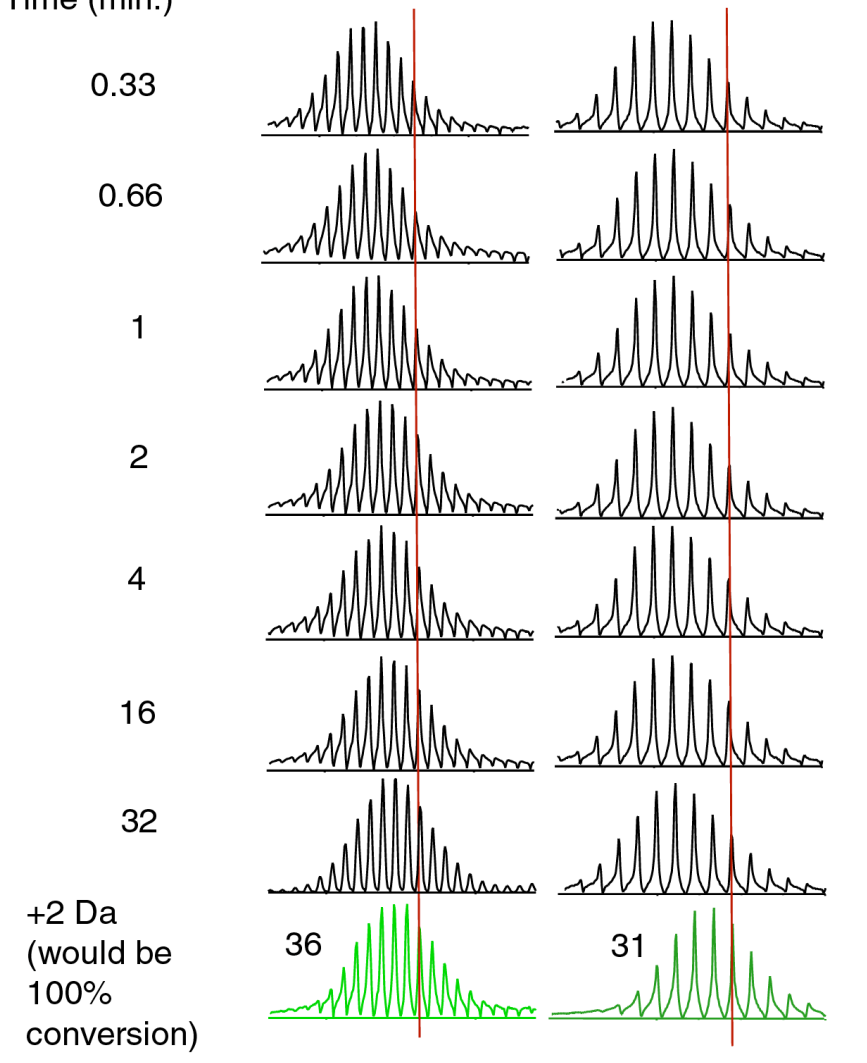

Figure s13. Time course. A) HPLC of $\mathrm{ACP}_{2} \mathrm{~B}$ ) ESI-FTMS, the green MS data are fraction 36 and 31 by themselves showing a 2 Da shift which represents $100 \%$ conversion. This data shows there is little amine incorporation into the $\mathrm{PCP}_{1}$ (estimated $<10 \%$ for the $\mathrm{PCP}_{1}$ ) while for the $\mathrm{ACP}_{2}$ there is amine transfer. 


\section{f. Reversibility of the amine transfer to MycA4N7}

The Nvoc-protected $\beta$-aminobutyryl-CoA was accessed in a straightforward manner from Nvocprotected $\beta$-aminobutyric acid. To a solution of Nvoc-protected $\beta$-aminobutyric acid ( $20 \mathrm{mg}, 0.061$ mmol) in tetrahydrofuran $(0.61 \mathrm{~mL})$ was added an aqueous solution $\left(0.61 \mathrm{~mL} \mathrm{H}_{2} \mathrm{O}\right)$ containing potassium carbonate $(21.3 \mathrm{mg})$, PyBOP $(47.6 \mathrm{mg}, 0.091 \mathrm{mmol})$ and coenzyme A, trilithium salt. The reaction was stirred at room temperature for $45 \mathrm{~min}$, then acidified by the addition of $0.61 \mathrm{~mL}$ of triflouroacetic acid and purified directly by preparative HPLC (C18 silica gel, 0-40\% acetonitrile:0.1\% triflouroacetic acid in water over $30 \mathrm{~min}$ ) to provide $32.3 \mathrm{mg}$ of a pale yellow solid (49.2\%). This was characterized by MALDI mass spectroscopy: (calculated: 1077.8; found: 1077.8) and UV-vis $\left(\lambda_{\max }=\right.$ 202, 249 and $349 \mathrm{~nm})$.

MycA4N7 (400 $\mu \mathrm{l}, 860 \mu \mathrm{g}$ ) was incubated with $3.5 \mu \mathrm{M} \mathrm{Sfp}, 8 \mathrm{mM} \mathrm{MgCl}_{2}$ with the Nvocprotected $\beta$-aminobutyryl-CoA for 2 hours in the dark. At this point $200 \mu \mathrm{L}$ of the reaction mixture was placed in a quartz cuvette and irradiated at $365 \mathrm{~nm}$ for $20 \mathrm{~min}$. Following the irradiation both the nonirradiated sample and irradiated sample were treated with trypsin $(5 \mu \mathrm{g})$ for $5 \mathrm{~min}$ (in the dark) before quenching with $50 \mu 1$ of $10 \%$ formic acid and separated by HPLC. Fractions 31, 32, 33, 36, 37 and 38 were collected, lyophilized in the dark and analyzed by FTMS. 


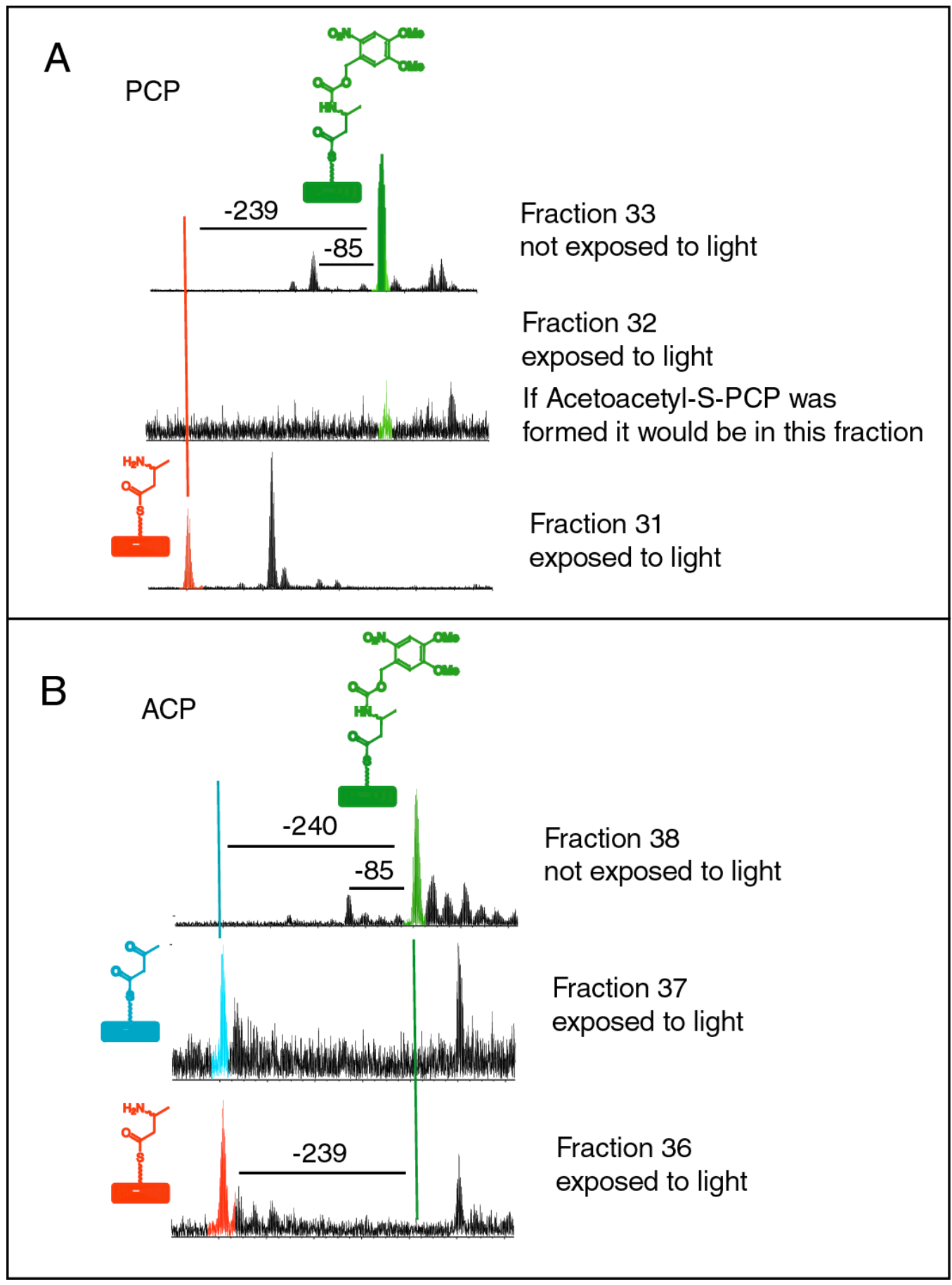

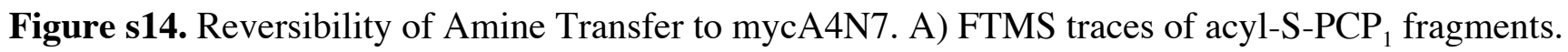
Top Nvoc protected aminobutyryl-S-PCP ${ }_{1}$, middle; fraction 32 when Nvoc protected aminobutyryl-S$\mathrm{PCP}_{1}$ was irradiated with $\mathrm{UV}_{365}$ for $20 \mathrm{~min}$. Bottom, Nvoc protected aminobutyryl-S-PCP ${ }_{1}$ exposed to

UV fraction 31 corresponding to aminobutyrate loaded-S-PCP ${ }_{1}$ B) FTMS traces of acyl-S-ACP ${ }_{2}$ fragments without UV exposure(top trace) and with UV exposure (middle and bottom trace). 
X. Scheme S1: Mechanism of PLP mediated amine transfer.

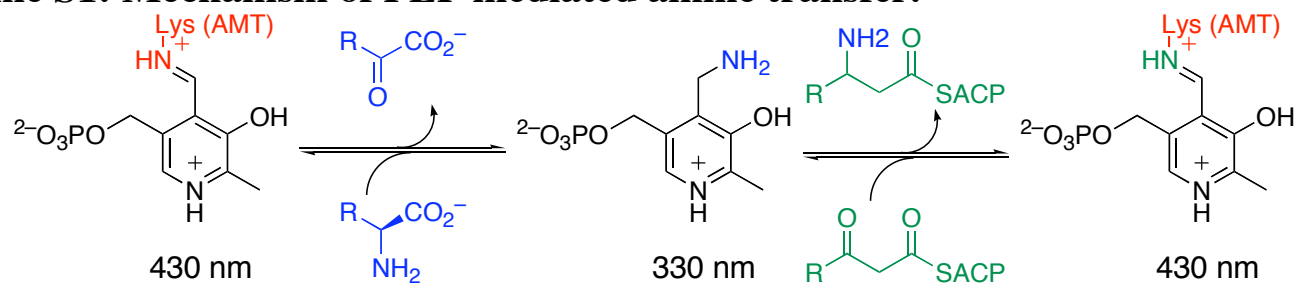

Scheme s1. Mechanism of PLP Mediated Amine Transfer. 